\title{
BMJ Open Determinants of accessing healthcare in Sub-Saharan Africa: a mixed-effect analysis of recent Demographic and Health Surveys from 36 countries
}

\author{
Zemenu Tadesse Tessema (D) , ${ }^{1}$ Misganaw Gebrie Worku (D) ,2 \\ Getayeneh Antehunegn Tesema (D) , ${ }^{1}$ Tesfa Sewunet Alamneh (D) ,' \\ Achamyeleh Birhanu Teshale (D) , ${ }^{1}$ Yigizie Yeshaw (D) ," Adugnaw Zeleke Alem (D) ,1 \\ Hiwotie Getaneh Ayalew, ${ }^{4}$ Alemneh Mekuriaw Liyew ${ }^{1}$
}

To cite: Tessema ZT, Worku MG, Tesema GA, et al. Determinants of accessing healthcare in SubSaharan Africa: a mixed-effect analysis of recent Demographic and Health Surveys from 36 countries. BMJ Open 2022;12:e054397. doi:10.1136/ bmjopen-2021-054397

- Prepublication history and additional supplemental material for this paper are available online. To view these files, please visit the journal online (http://dx.doi.org/10.1136/ bmjopen-2021-054397).

Received 14 June 2021 Accepted 12 November 2021

Check for updates

(c) Author(s) (or their employer(s)) 2022. Re-use permitted under CC BY-NC. No commercial re-use. See rights and permissions. Published by BMJ.

${ }^{1}$ Epidemiology and Biostatistics, University of Gondar College of Medicine and Health Sciences, Gondar, Ethiopia

${ }^{2}$ Human Anatomy, University of Gondar, Gondar, Ethiopia ${ }^{3}$ Medical Physiology, University of Gondar College of Medicine and Health Sciences, Gondar, Ethiopia

${ }^{4}$ Department of Midwifery, School of Nursing and Midwifery, College of Medicine and Health Sciences, Wollo University, Dessie, Ethiopia

Correspondence to

Zemenu Tadesse Tessema; zemenut1979@gmail.com

\section{ABSTRACT}

Objective This study aimed to assess the determinants of accessing healthcare among reproductive-age women in Sub-Saharan Africa (SSA).

Design, setting and analysis Cross-sectional data were sourced from recent Demographic and Health Surveys in 36 SSA countries. We employed mixed-effect analysis to identify the determinants of accessing healthcare in SSA. OR and its $95 \% \mathrm{Cl}$ were reported for determinants associated with accessing healthcare.

Outcome The outcome for this study was whether accessing healthcare was a 'big problem' or 'not a big problem'. Responses to these questions were categorised as a big problem and not a big problem.

Participants A total weighted sample of 500439 reproductive-age (15-49 years) women from each country's recent Demographic and Health Surveys from 2006 to 2018 were included in this study.

Results The pooled prevalence of healthcare access among reproductive-age women in SSA was $42.56 \%$ (95\% Cl $42.43 \%$ to $42.69 \%)$. The results of the mixedeffect analysis revealed that the determinants of accessing healthcare were urban residence (adjusted $\mathrm{OR}(\mathrm{AOR})=1.25,95 \% \mathrm{Cl} 1.34$ to 1.73$)$, ability to read and write (AOR=1.15, 95\% $\mathrm{Cl} 1.22$ to 1.28 ), primary education ( $A 0 \mathrm{R}=1.08,95 \% \mathrm{Cl} 1.07$ to 1.12), secondary education and above (AOR=1.12, 95\% $\mathrm{Cl} 1.10$ to 1.14), husband with primary education ( $\mathrm{AOR}=1.06,95 \% \mathrm{Cl} 1.07$ to 1.1.12), husband with secondary education and above $(A 0 R=1.22$, $95 \% \mathrm{Cl} 1.18$ to 1.27), middle wealth index ( $\mathrm{AOR}=1.43$, $95 \% \mathrm{Cl} 1.40$ to 1.47), rich wealth index ( $\mathrm{AOR}=2.19,95 \% \mathrm{Cl}$ 2.13 to 2.24) and wanted pregnancy (AOR=1.27, 95\% Cl 1.19 to 1.29$)$.

Conclusion Healthcare access in SSA was found at $42.56 \%$, which is very low even if Sustainable Development Goal 3.8 targeted universal health coverage for everyone so they can obtain the health services they need. The major determinants of healthcare access among reproductive-age women in SSA were urban residence, higher educational level, higher wealth index and wanted pregnancy. The findings of this study suggest and recommend strengthening and improving healthcare access for women who reside in the countryside,

\section{Strengths and limitations of this study}

- The study included 36 Sub-Saharan African countries and each country's Demographic and Health Survey data set is representative of the country and is generalisable.

- The study used mixed-effect analysis which considers clustering effect in order to provide reliable estimates.

- Incorporating a large sample size with adequate power allows detection of the true effect of independent variables.

- This study has its own limitation, that is, the findings do not establish a cause and effect relationship due to the cross-sectional nature of the data/surveys.

women with low level of education and women of low socioeconomic status.

\section{INTRODUCTION}

Globally, $50 \%$ of people are unable to access basic health services, as reported by the World Bank and the WHO in 2017. ${ }^{1}$ In Africa, 11 million people are in poverty as a result of using their household income to access essential healthcare services. ${ }^{2}$ There is wide discrepancy in accessibility and availability of essentials in Sub-Saharan Africa (SSA) and in Southern Asia. ${ }^{3}$

Healthcare access indicates the affordability, accessibility, availability and acceptability of services in order to achieve the best health outcome. ${ }^{4}$ Access to maternal health services is different among women due to them having less land, wealth and properties despite carrying a higher burden of labour, which has a significant role in the society. Also, in most situations, girls are less fed and educated and physically restricted in certain contexts. $^{5-7}$ 
Globally, women suffer from healthcare inequalities, which lead to excess mortality in all periods of life. ${ }^{8}$ Maternal health service refers to providing health service to women during pregnancy, childbearing and postpartum period, and includes antenatal care visits, delivery care and postnatal care services. ${ }^{9}$ Although Sustainable Development Goal (SDG) target 3.8 aims to provide universal health coverage, 400 million people in the world lack access to essential health services. ${ }^{10}$ Previous studies have provided some evidence on the factors associated with healthcare access, including social, demographic and economic determinants such as marital status ${ }^{11}$ residence, ${ }^{12}$ age,${ }^{13}$ literacy, ${ }^{14}$ education, ${ }^{14}$ wealth index, ${ }^{15}$ birth order, ${ }^{16}$ wanted pregnancy ${ }^{17}$ and women empowerment. ${ }^{18}$

Different empirical evidence related to healthcare access among reproductive-age women has been explored at the country level. Meanwhile, accessing healthcare is a big challenge. There are limited studies that have incorporated all SSA countries and multicountry Demographic and Health Survey (DHS) data sets. This study attempted to generate new evidence by including data from all countries in SSA from 2006 to 2018.

This study aimed to identify the potential factors associated with healthcare access among the reproductive age group in SSA. The results will help improve coverage of access to healthcare and to design an intervention strategy to address issues of poor maternal health status and outcomes.

\section{METHODS}

\section{Data source}

Data for this study were sourced from the most recent surveys in 36 SSA countries from 2006 to 2018. The DHS programme collects data that are comparable across lowincome and middle-income countries. The programme designs the same manual, code, value level, variable name and procedure in more than 90 countries across the world. The SSA countries included in this study are listed in table 1. Details can be found in our previously published work. ${ }^{19-21}$ The inclusion and exclusion criteria for SSA countries are shown in figure 1. Data were collected from each country's survey year 5 years preceding the survey. The DHS collects data on HIV/AIDS, nutrition, child health, child nutrition, reproductive health, family planning, marriage, fertility and mortality. Individual record files were used in this study.

A two-stage stratified sampling method was used to select study participants. First, the enumeration area was selected based on each country frame developed from the previous census conducted. Second, households from each enumeration area were selected. The full sampling procedure is found elsewhere..$^{22}$ A total of 500439 reproductive-age women were eligible for this study. Due to the observational nature of the study, the Strengthening the Reporting of Observational Studies in Epidemiology checklist was used and is provided in online supplemental file 1 .
Table 1 Pooled Demographic and Health Survey (DHS) data from 36 Sub-Saharan African countries

\begin{tabular}{|c|c|c|}
\hline Country & DHS year & $\begin{array}{l}\text { Sample size } \\
\text { (500 439) }\end{array}$ \\
\hline Southern region of Africa & & 30140 \\
\hline Lesotho & 2014 & 6621 \\
\hline Namibia & 2013 & 10081 \\
\hline Swaziland & $2006 / 2007$ & 4987 \\
\hline South Africa & 2016 & 8514 \\
\hline Central region of Africa & & 88207 \\
\hline Angola & $2015 / 2016$ & 14379 \\
\hline Democratic Republic of Congo & $2013 / 2014$ & 18379 \\
\hline Congo & $2011 / 2012$ & 10819 \\
\hline Cameroon & 2011 & 15426 \\
\hline Gabon & 2012 & 8422 \\
\hline Sao Tome and Principe & $2008 / 2009$ & 2615 \\
\hline Chad & $2014 / 2015$ & 17719 \\
\hline Eastern region of Africa & & 193949 \\
\hline Burundi & 2010 & 17269 \\
\hline Ethiopia & 2016 & 15683 \\
\hline Kenya & 2014 & 31079 \\
\hline Comoros & 2012 & 5329 \\
\hline Madagascar & $2008 / 2009$ & 17375 \\
\hline Malawi & $2015 / 2016$ & 24562 \\
\hline Mozambique & 2011 & 13745 \\
\hline Rwanda & $2014 / 2015$ & 13497 \\
\hline Tanzania & $2015 / 2016$ & 13266 \\
\hline Uganda & 2011 & 18266 \\
\hline Zambia & 2018 & 13683 \\
\hline Zimbabwe & $2013 / 2014$ & 9955 \\
\hline Western region of Africa & & 188143 \\
\hline Burkina Faso & 2010 & 17087 \\
\hline Benin & 2017 & 15928 \\
\hline Cote d'Ivoire & 2011 & 10060 \\
\hline Ghana & 2014 & 9396 \\
\hline Gambia & 2013 & 10233 \\
\hline Guinea & 2018 & 10233 \\
\hline Liberia & 2013 & 9239 \\
\hline Mali & 2018 & 10519 \\
\hline Nigeria & 2018 & 41821 \\
\hline Niger & 2012 & 11160 \\
\hline Sierra Leone & $2010 / 2011$ & 16658 \\
\hline Senegal & $2010 / 2011$ & 15688 \\
\hline Togo & $2013 / 2014$ & 9480 \\
\hline
\end{tabular}

\section{Measurement of variables}

Outcome variable

The outcome variable was accessibility. Most studies have ignored travel time and transport cost when looking at access to health facilities. In the DHS data, women were asked whether a range of factors would be a big problem 


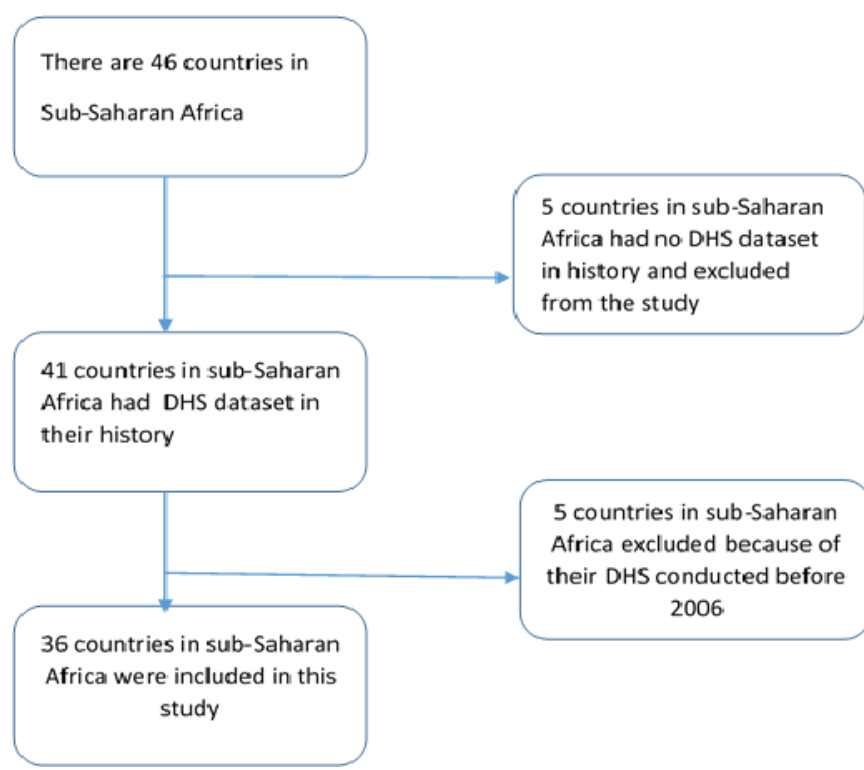

Figure 1 Diagrammatic representation of Sub-Saharan African countries included in the study. DHS, Demographic and Health Survey.

for them when accessing healthcare. We generated a composite outcome variable using each country's DHS standard question. The questions included the following:

- Getting the money needed for treatment (big problem/not a big problem).

- Distance to a healthcare facility (big problem/not a big problem).

- Having to take transport (big problem/not a big problem).

- Not wanting to go alone (big problem/not a big problem).

The responses to the questions asked are 'big problem' and 'not a big problem'. If a woman faces at least one problem, access to healthcare is considered a big problem and is coded 1 or 0 otherwise.

\section{Explanatory variables}

After reviewing different types of literature, ${ }^{12} 131723-25$ variables were retrieved from the DHS data set. Variables at the individual, community and regional levels were considered in this study. Individual-level variables include age group, literacy level, women's educational status, marital status, husband's educational status, maternal occupation status, media exposure, wealth status, birth order and wanted pregnancy, whereas residence was a community-level variable and region a regional-level variable.

\section{Analytical procedure}

In this study, both descriptive and inferential analyses were done. The survey year and the number of reproductive-age women in each country are presented in the tables. The weighted number of reproductive-age women and the weighted percentage of women for each sociodemographic variable are presented in table 2. Model comparison is presented in table 3. The results of the multivariable generalised mixed-effect model are presented to see the effect size of the association between the outcome and the independent variables.

STATA V.14 software was used for analysis. First, each country was given a code and then appended together to create a single data set that represents the SSA countries. There are individual-level and community-level variables in the data set. The nature of the DHS data set is hierarchical and needs advanced statistical techniques to account for variability. The generalised linear mixedeffect model was fitted. Both fixed and random estimates were reported. For fixed-effect estimates, adjusted OR (AOR) and its 95\% CI were reported to see the effect size of the association between healthcare access problem and the independent variables (table 4). For random-effect estimates, intraclass correlation and median OR were reported (table 3 ). First, in the bivariable analysis, variables with a p value less than 0.2 were taken as a candidate variable for the final model. Variables in the final model with a $p$ value less than 0.005 were declared as determinants significantly associated with accessing healthcare in SSA.

\section{Patient and public involvement}

There is no direct public and patient involvement in the design and conduct of this research.

\section{RESULTS}

A total of 500439 reproductive-age women 5 years preceding the survey in SSA countries were included in this study. Of these, 193949 (38.76\%) respondents were from the eastern region of Africa and 30140 (6.02\%) respondents were from the southern region. A total of 313428 (62.63\%) respondents were rural residents. Among the respondents, 158532 (31.68) women and $124184(37.32 \%)$ men had no formal education, and $195653(39.10 \%)$ respondents were of poor wealth status (table 2).

\section{Pooled prevalence of healthcare access in SSA}

The pooled prevalence of healthcare access in SSA was $42.56 \%$ (95\% CI 42.43 to 42.69 ), with the highest rate of healthcare access in the southern region of Africa at $49 \%$ (95\% CI 48 to 49 ) and the lowest rate of healthcare access in the central region at $37 \%$ (95\% CI 37 to 37). Among the SSA countries, the highest rate of healthcare access was from Kenya at 77\% (95\% CI 76 to 77) and the lowest rate of healthcare access was from Gabon and Sao Tome at $17 \%$ for both countries (95\% CI 16 to 18 and $95 \%$ CI 15 to 18 , respectively; figure 2 ).

\section{Model comparison}

Model comparison was done and a mixed-effect logistic regression model was chosen over ordinary logistic regression model due to low deviance. Furthermore, the intraclass correlation coefficient value was $12.09 \%$ (95\% CI 11.17 to 13.08 ) and the median OR was 1.44 , indicating 
Table 2 Socioeconomic and demographic characteristics of reproductive-age women in Sub-Saharan Africa

\begin{tabular}{|c|c|c|c|}
\hline Variable & Category & Weighted frequency & $\%$ \\
\hline \multirow[t]{4}{*}{ Region } & Southern Africa & 30140 & 6.02 \\
\hline & Central Africa & 88207 & 17.63 \\
\hline & Eastern Africa & 193949 & 38.76 \\
\hline & Western Africa & 188143 & 37.60 \\
\hline \multirow[t]{2}{*}{ Residence } & Rural & 313428 & 62.63 \\
\hline & Urban & 187011 & 37.37 \\
\hline \multirow[t]{3}{*}{ Age group } & $15-24$ & 198907 & 39.75 \\
\hline & $25-34$ & 157282 & 31.43 \\
\hline & $35-49$ & 144250 & 28.82 \\
\hline \multirow[t]{2}{*}{ Marital status } & Single & 136519 & 27.28 \\
\hline & Married & 363920 & 72.72 \\
\hline \multirow[t]{2}{*}{ Literacy level } & Cannot read and write & 212244 & 42.41 \\
\hline & Can read and write & 288195 & 57.59 \\
\hline \multirow[t]{3}{*}{ Maternal education } & No education & 158532 & 31.68 \\
\hline & Primary education & 163734 & 32.72 \\
\hline & Secondary education and above & 178173 & 35.60 \\
\hline \multirow{3}{*}{$\begin{array}{l}\text { Husband's education } \\
(\mathrm{n}=332753)\end{array}$} & No education & 124184 & 37.32 \\
\hline & Primary education & 90831 & 27.30 \\
\hline & Secondary education and above & 117738 & 35.38 \\
\hline \multirow[t]{2}{*}{ Maternal occupation } & No & 155707 & 31.11 \\
\hline & Yes & 344732 & 68.89 \\
\hline \multirow[t]{3}{*}{ Wealth index } & Poor & 195653 & 39.10 \\
\hline & Middle & 95039 & 18.99 \\
\hline & Rich & 209747 & 41.91 \\
\hline \multirow[t]{2}{*}{ Media exposed } & Yes & 350348 & 70.02 \\
\hline & No & 150023 & 29.98 \\
\hline \multirow[t]{3}{*}{ Birth order $(n=492403)$} & 1 & 70740 & 14.37 \\
\hline & $2-4$ & 170095 & 34.54 \\
\hline & $5+$ & 251568 & 51.09 \\
\hline \multirow[t]{2}{*}{ Wanted pregnancy $(n=255685)$} & No & 17434 & 6.82 \\
\hline & Yes & 238251 & 93.18 \\
\hline
\end{tabular}

that if we randomly select two women from different clusters, women from a cluster with better healthcare access increased by $44 \%$ as compared with women with low healthcare access. Besides, the likelihood ratio test was (likelihood ratio test vs logistic model: chibar2 $(01)=1486.67$ Prob $>=$ chibar2 $=<0.001)$, which informed that the mixed-effect logistic regression model (generalised linear mixed effect model (GLMM)) is the better model over the basic logistic regression model (table 3).

\section{Determinants of accessing healthcare}

In the multivariable mixed-effect logistic regression model, region, residence, literacy level, maternal and husband educational status, media exposure, wealth status, and wanted pregnancy were statistically associated with accessing healthcare in SSA.
Women living in the central, eastern and western regions of Africa had decreased likelihood of accessing healthcare, at $25 \%, 23 \%$ and $31 \%$ (AOR $=0.75,95 \%$ CI 0.71 to $0.80 ; \mathrm{AOR}=0.77,95 \% \mathrm{CI} 0.73$ to $0.81 ; \mathrm{AOR}=0.69$, $95 \%$ CI 0.65 to 0.73$)$, respectively, as compared with women living in the southern region. Women who reside in urban areas are 1.25 times more likely $(\mathrm{AOR}=1.25$, $95 \%$ CI 1.22 to 1.28 ) to access healthcare than women living in rural areas. Women who can read and write are 1.15 times more likely (AOR $=1.15,95 \%$ CI 1.08 to 1.18 ) to access healthcare than women who cannot read and write. Women with primary and secondary and above education are 1.08 and 1.12 times more likely $(\mathrm{AOR}=1.08,95 \% \mathrm{CI}$ 1.07 to 1.12 ; $\mathrm{AOR}=1.22,95 \%$ CI 1.10 to 1.14 ) to access healthcare than women who had no formal education, 
Table 3 Model comparison and random-effect results for the final model

\begin{tabular}{lcl}
\hline Parameter & $\begin{array}{l}\text { Standard logistic } \\
\text { regression }\end{array}$ & $\begin{array}{l}\text { Mixed-effect logistic } \\
\text { regression analysis } \\
\text { (GLMM) }\end{array}$ \\
\hline LLR & -144966 & -144223 \\
Deviance & 289932 & 288466 \\
ICC & & $12.09(11.17,13.08)$ \\
LR test & & $\begin{array}{l}\text { LR test vs logistic model: } \\
\text { chibar2(01)=1486.67 }\end{array}$ \\
& & Prob>=chibar2=<0.001 \\
MOR & & $1.44(1.40,1.49)$ \\
Cluster variance & & $0.1526(0.1289,0.1806)$ \\
\hline
\end{tabular}

GLMM, generalised linear mixed effect model; ICC, intraclass correlation coefficient; LLR, log-likelihood ratio; LR test, likelihood ratio test; MOR, median OR. respectively. Women whose husbands had primary and secondary and above education are 1.06 and 1.22 times more likely $(\mathrm{AOR}=1.08,95 \%$ CI 1.07 to 1.12 ; $\mathrm{AOR}=1.22$, $95 \%$ CI 1.10 to 1.14 ) to access healthcare than women whose husband had no formal education. The odds of accessing healthcare among media-exposed women increased by $15 \%$ compared with women who were not exposed to mass media ( $\mathrm{AOR}=1.08$, 95\% CI 1.07 to 1.12). Women below the middle and rich wealth status are 1.43 and 2.19 times more likely $(\mathrm{AOR}=1.43,95 \% \mathrm{CI}$ 1.40 to 1.47 ; AOR=2.19, 95\% CI 2.13 to 2.24) to access healthcare than poor women, respectively. The odds of accessing healthcare among women who wanted pregnancy increased by $24 \%$ compared with women who did not want their pregnancy (table 4).

Table 4 Multivariable mixed-effect logistic regression analysis of determinants of healthcare access in Sub-Saharan Africa

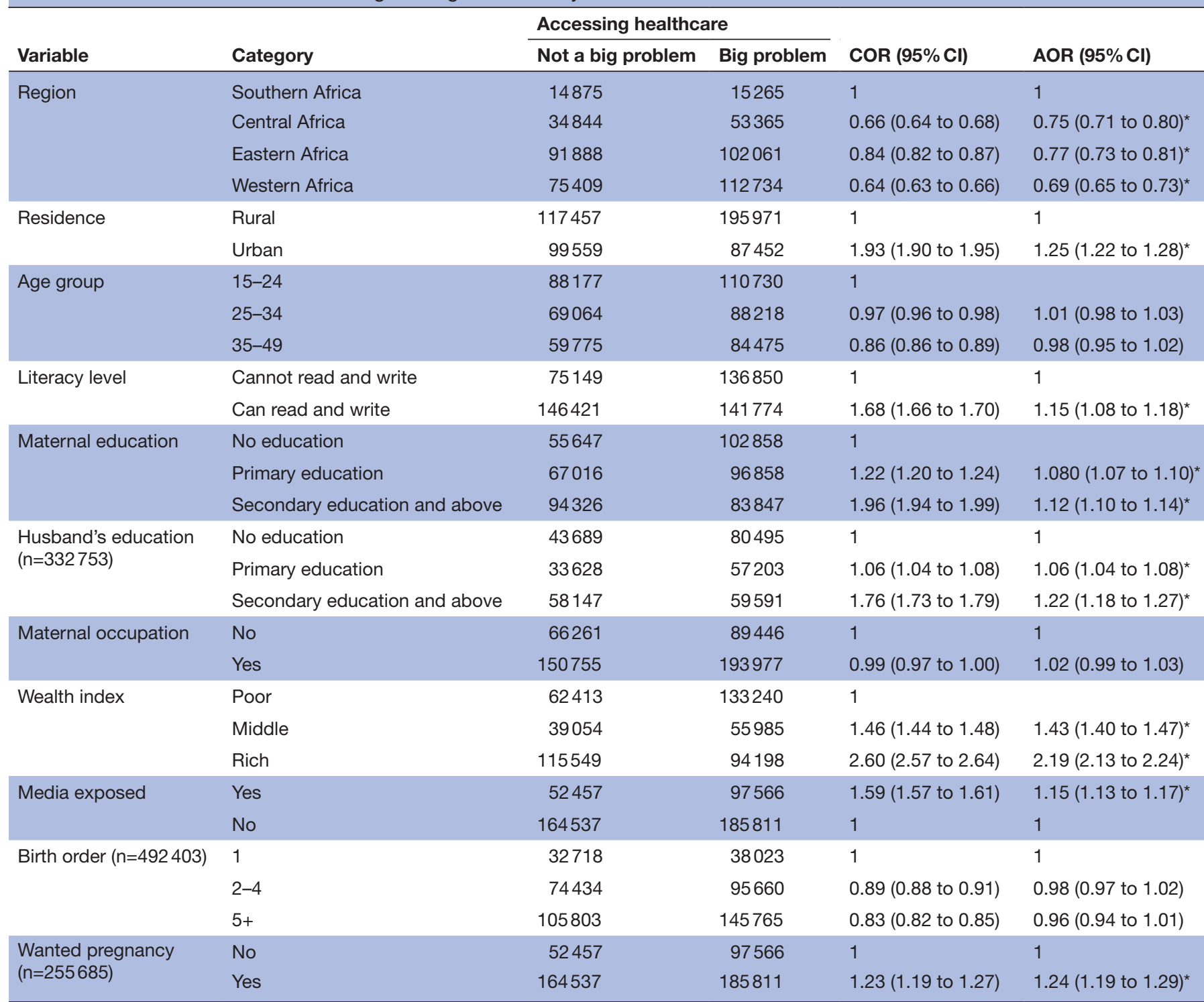

*significant at alpha $0.05,{ }^{* *}$ significant at alpha 0.01 and ${ }^{* * *}$ significant at alpha 0.001

AOR, adjusted odds ratio; COR, crude odds ratio. 


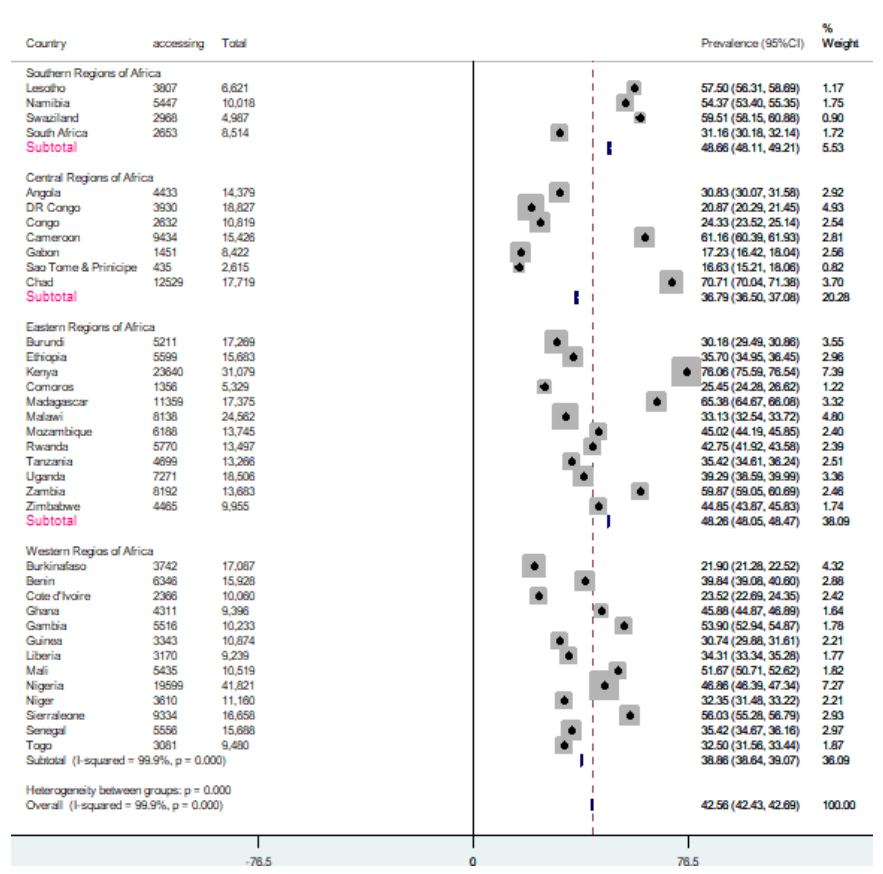

Figure 2 Forest plot of healthcare access among reproductive-age women in Sub-Saharan Africa. DR Congo, Democratic Republic of Congo.

\section{DISCUSSION}

This study attempted to assess the determinants of accessing healthcare among reproductive-age women in SSA. This study evidenced that the pooled prevalence of healthcare access in SSA was $42.56 \%$. The determinants associated with accessing healthcare are place of residence, maternal education, husband's education, wealth index and wanted pregnancy.

The pooled prevalence of healthcare access among reproductive-age women in SSA was $42.56 \%$ (95\% CI $42.43 \%$ to $42.69 \%$ ), which is consistent with Myanmar, ${ }^{18}$ South Africa ${ }^{26}$ and Tanzania. ${ }^{27}$

This study showed that literacy level is a determinant of healthcare access among reproductive-age women in SSA. Women who can read and write had higher odds of accessing healthcare compared with women who cannot read and write. This finding is consistent with studies conducted in other countries. ${ }^{14}$ The possible reason might be that women who can read and write can use the information they get from reading for health service utilisation.

This study revealed that women who reside in rural settings are less likely to access healthcare compared with women who reside in urban settings. This finding is consistent with studies done in Saudi Arabia, ${ }^{28}$ Athens, Greece, ${ }^{29}$ USA $^{30}$ Washington, ${ }^{31}$ East Africa ${ }^{32}$ and Ethiopia. ${ }^{17}$ Accessing healthcare is influenced by different infrastructures, such as roads, distance to a health facility and transport service, as well as access to education, economic limitations and the influence of sociocultural behaviours where women ask permission from their husbands before seeking healthcare. ${ }^{33}$
The findings also showed that maternal and husband education is a significant determinant of healthcare access among reproductive-age women in SSA. Women and husbands with low-level education are less likely to access healthcare compared with women and husbands with higher-level education. This finding is consistent with studies done in Africa, ${ }^{34}$ South Africa, ${ }^{35}$ SSA, ${ }^{26}$ WHO global health survey, ${ }^{36}$ and South Asia and SSA. ${ }^{37}$ The possible reason might be that education is a basis for everything and that educated people have better sources of information and use the health education they get from health institutions. Women and men of higher educational level benefit economically compared with uneducated women and men. ${ }^{23}$

Wealth index is another determinant of healthcare access among reproductive-age women in SSA. Women of better wealth index status had higher odds of accessing healthcare compared with the poorest women. This finding is consistent with studies done in Namibia, Kenya, Nepal, India, ${ }^{38}$ Myanmar, ${ }^{18}$ East Africa, ${ }^{32}$ Kenya, ${ }^{39}$ Ethiopia ${ }^{17}$ and SSA ${ }^{25} 40$ The possible reason might be that wealthy women can access healthcare because they can pay for their health services and have increased accessibility to healthcare. Meanwhile, it is a big problem for poor women as they are unable to pay for health services.

This study revealed that the odds of accessing healthcare among women who had wanted pregnancy increased by $24 \%$ compared with women who did not want their pregnancy. This finding is consistent with studies done in different countries, such as Tanzania, ${ }^{41} \mathrm{UK}^{42}$ and Ghana. ${ }^{24}$ The possible reason might be that women with unwanted pregnancy have a negative attitude towards maternal health service utilisation, such as Antenatal (ANC) visits, delivery and Postnatal (PNC) services.

Living regions in Africa also had a significant effect on healthcare access among reproductive-age women in SSA. Women living in the central, eastern and western regions of Africa had decreased likelihood of accessing healthcare at $25 \%, 23 \%$ and $31 \%$, respectively, compared with women living in the southern region. This is due to the fact that the southern region of Africa had better economic status and health infrastructure compared with other regions. ${ }^{43}$

\section{Strengths and limitations of this study}

The study included 36 SSA countries and each country's DHS data set is representative of the country and is generalisable. The study used mixed-effect analysis which considers clustering effect in order to provide reliable estimates. Incorporating a large sample size with adequate power allows detection of the true effect of independent variables. This study has its own limitation, that is, the findings do not establish a cause and effect relationship due to the cross-sectional nature of the data/surveys.

\section{CONCLUSION}

Healthcare access in SSA was found at $42.56 \%$, which is very low even if SDG 3.8 targeted universal health 
coverage for everyone so they can obtain the health services they need. The major determinants of healthcare access among reproductive-age women in SSA were urban residence, higher educational level, higher wealth index and wanted pregnancy. The findings of this study suggest and recommend strengthening and improving healthcare access for women who reside in the countryside, women with low level of education and women of low socioeconomic status.

Acknowledgements We would like to thank the Measure DHS programme for providing the data set.

Contributors Conceptualisation: ZTT, MGW, GAT, TSA, ABT, YY, AZA, HGA and AML. Data curation: ZTT, MGW, GAT, TSA, ABT, YY, AZA, HGA and AML. Investigation: ZTT, MGW, GAT, TSA, ABT, YY, AZA, HGA and AML. Methodology: ZTT, MGW, GAT, TSA, ABT, YY, AZA, HGA and AML. Software: ZTT, MGW, GAT, TSA, ABT, YY, AZA, HGA and AML. Validation: ZTT, MGW, GAT, TSA, ABT, YY, AZA, HGA and AML. Writing: ZTT, MGW, GAT, TSA, ABT, YY, AZA, HGA and AML. Writing - review: ZTT, YY, AML, GAT, TSA, MGW and ABT. Writing - editing: AZA, ZTT, MGW, GAT, TSA, ABT, YY, HGA and AML. All authors read and approved the manuscript. ZTT is responsible for the overall content as the guarantor.

Funding The authors have not declared a specific grant for this research from any funding agency in the public, commercial or not-for-profit sectors.

Competing interests None declared.

Patient consent for publication Not required.

Ethics approval Permission to get access to the data was obtained from the Measure DHS programme through an online request at https://dhsprogram.com/ and the data used were publicly available with no personal identifier. Data were obtained from the Measure DHS programme through an online request and the data used were publicly available with no personal identifier (The Demographic Health Survey Program. Guide to DHS statistics. Available: https://dhsprogram.com/data/ dataset_admin/index.cfm)

Provenance and peer review Not commissioned; externally peer reviewed.

Data availability statement Data are available upon reasonable request. Data are available online and can be accessed from www.measuredhs.com.

Supplemental material This content has been supplied by the author(s). It has not been vetted by BMJ Publishing Group Limited (BMJ) and may not have been peer-reviewed. Any opinions or recommendations discussed are solely those of the author(s) and are not endorsed by BMJ. BMJ disclaims all liability and responsibility arising from any reliance placed on the content. Where the content includes any translated material, BMJ does not warrant the accuracy and reliability of the translations (including but not limited to local regulations, clinical guidelines, terminology, drug names and drug dosages), and is not responsible for any error and/or omissions arising from translation and adaptation or otherwise.

Open access This is an open access article distributed in accordance with the Creative Commons Attribution Non Commercial (CC BY-NC 4.0) license, which permits others to distribute, remix, adapt, build upon this work non-commercially, and license their derivative works on different terms, provided the original work is properly cited, appropriate credit is given, any changes made indicated, and the use is non-commercial. See: http://creativecommons.org/licenses/by-nc/4.0/.

\section{ORCID iDs}

Zemenu Tadesse Tessema http://orcid.org/0000-0003-3878-7956

Misganaw Gebrie Worku http://orcid.org/0000-0002-7647-6449

Getayeneh Antehunegn Tesema http://orcid.org/0000-0001-6812-1659

Tesfa Sewunet Alamneh http://orcid.org/0000-0002-4830-931X

Achamyeleh Birhanu Teshale http://orcid.org/0000-0002-7572-9993

Yigizie Yeshaw http://orcid.org/0000-0003-4587-7925

Adugnaw Zeleke Alem http://orcid.org/0000-0002-1928-8548

\section{REFERENCES}

1 WHO WB. Half the world lacks access to essential health services, 100 million still pushed into extreme poverty because of health expenses, 2017.
2 Global Agenda. How Africa and Asia are joining forces on universal healthcare [Internet]. Available: https://www.weforum.org/agenda/ 2019/04/universal-health-coverage-uhc-asia-africa-kenya-thailandjapan-egypt/

$3 \mathrm{WHO}$. The 13 biggest threats to global health according to WHO, 2020.

4 Gulliford M, Figueroa-Munoz J, Morgan M, et al. What does 'access to health care' mean? J Health Serv Res Policy 2002;7:186-8.

5 Pega F, Veale JF. The case for the world Health organization's Commission on social determinants of health to address gender identity. Am J Public Health 2015;105:e58-62.

6 Sen G, Östlin P. Gender inequity in health: why it exists and how we can change it. Taylor \& Francis, 2008.

7 Shannon G, Jansen M, Williams K, et al. Gender equality in science, medicine, and global health: where are we at and why does it matter? Lancet 2019;393:560-9.

8 Myatra SN, Tripathy S, Einav S. Global health inequality and women beyond maternal health. Anaesthesia 2021;76 Suppl 4:6-9.

9 WHO. Maternal health, 2016. Available: http://www.who.int/ maternal_child_adolescent/topics/maternal/en/

10 WHO. How many people lack access to health care? (hint: more than who and the world bank report), 2019. Available: https://oneill.law. georgetown.edu/how-many-people-lack-access-to-health-care-hintmore-than-who-and-the-world-bank-report/

11 Pandey KR, Yang F, Cagney KA, et al. The impact of marital status on health care utilization among Medicare beneficiaries. Medicine 2019;98:e14871.

12 Yang Y-T, Iqbal U, Ko H-L, et al. The relationship between accessibility of healthcare facilities and medical care utilization among the middle-aged and elderly population in Taiwan. Int J Qual Heal Care 2015;27:222-31.

13 National Academies of Sciences, Engineering and M. Health-Care utilization as a proxy in disability determination. health-care utilization as a proxy in disability determination, 2018.

14 Cho. HHS public access. Physiol Behav 2016;176:100-6.

15 Minyihun A, Tessema ZT. Determinants of access to health care among women in East African countries: a multilevel analysis of recent demographic and health surveys from 2008 to 2017. Risk Manag Healthc Policy 2020;13:1803-13.

16 Pruckner GJ, Schneeweis N, Schober T, et al. Birth order, parental health investment, and health in childhood. SSRN J 2019.

17 Tamirat KS, Tessema ZT, Kebede FB. Factors associated with the perceived barriers of health care access among reproductive-age women in Ethiopia: a secondary data analysis of 2016 Ethiopian demographic and health survey. BMC Health Serv Res 2020;20:1-8.

18 Htun NMM, Hnin ZL, Khaing W. Empowerment and health care access barriers among currently married women in Myanmar. BMC Public Health 2021;21:1-9.

19 Tessema ZT, Teshale AB, Tesema GA, et al. Determinants of completing recommended antenatal care utilization in sub-Saharan from 2006 to 2018: evidence from 36 countries using demographic and health surveys. BMC Pregnancy Childbirth 2021;21:1-12.

20 Tessema ZT, Yazachew L, Tesema GA, et al. Determinants of postnatal care utilization in sub-Saharan Africa: a meta and multilevel analysis of data from 36 sub-Saharan countries. Ital J Pediatr 2020;46:1-11.

21 Tessema ZT, Tamirat KS, Teshale AB, et al. Prevalence of low birth weight and its associated factor at birth in sub-Saharan Africa: a generalized linear mixed model. PLoS One 2021;16:1-13.

22 Demographic T, Program HS. Guide to DHS statistics. Available: https://dhsprogram.com/data/dataset_admin/index.cfm

23 Becker G, Newsom E. Socioeconomic status and dissatisfaction with health care among chronically ill African Americans. Am J Public Health 2003;93:742-8.

24 Sakeah E, Okawa S, Rexford Oduro A, et al. Determinants of attending antenatal care at least four times in rural Ghana: analysis of a cross-sectional survey. Glob Health Action 2017;10:1291879.

25 Pons-Duran C, Lucas A, Narayan A, et al. Inequalities in sub-Saharan African women's and girls' health opportunities and outcomes: evidence from the demographic and health surveys. J Glob Health 2019;9:010410.

26 Seidu A-A. Mixed effects analysis of factors associated with barriers to accessing healthcare among women in sub-Saharan Africa: insights from demographic and health surveys. PLoS One 2020;15:1-16.

27 Nisingizwe MP, Tuyisenge G, Hategeka C, et al. Are perceived barriers to accessing health care associated with inadequate antenatal care visits among women of reproductive age in Rwanda? BMC Pregnancy Childbirth 2020;20:88.

28 Almalki M, FitzGerald G, Clark M. The nursing profession in Saudi Arabia: an overview. Int Nurs Rev 2011;58:304-11. 
29 Pappa E, Niakas D. Assessment of health care needs and utilization in a mixed public-private system: the case of the Athens area. BMC Health Serv Res 2006;6:1-11.

30 Bhatt J, Bathija P. Ensuring access to quality health care in vulnerable communities. Acad Med 2018;93:1271-5.

31 National Academies of Sciences E, Medicine. Health-care utilization as a proxy in disability determination, 2018

32 Tessema ZT, Minyihun A. Utilization and determinants of antenatal care visits in East African countries: a multicountry analysis of demographic and health surveys. Adv Public Heal 2021;2021:1-9.

33 Munguambe $\mathrm{K}$, Boene $\mathrm{H}$, Vidler $\mathrm{M}$, et al. Barriers and facilitators to health care seeking behaviours in pregnancy in rural communities of southern Mozambique. Reprod Health 2016;13:83-97.

34 Tsala Dimbuene Z, Amo-Adjei J, Amugsi D, et al. Women's education and utilization of maternal health services in Africa: a multi-COUNTRY and socioeconomic status analysis. J Biosoc Sci 2018;50:725-48.

35 Tsawe M, Susuman AS. Determinants of access to and use of maternal health care services in the Eastern Cape, South Africa: a quantitative and qualitative investigation. BMC Res Notes 2014;7:1-10.

36 Karlsen S, Say L, Souza J-P, et al. The relationship between maternal education and mortality among women giving birth in health care institutions: analysis of the cross sectional WHO global survey on maternal and perinatal health. BMC Public Health 2011;11:1-10.

37 Tey N-P, Lai S-li. Correlates of and barriers to the utilization of health services for delivery in South Asia and sub-Saharan Africa. Scientific World J 2013;2013:1-11.

38 Namasivayam A, Osuorah DC, Syed R, et al. The role of gender inequities in women's access to reproductive health care: a population-level study of Namibia, Kenya, Nepal, and India. Int $J$ Womens Health 2012;4:351-64.

39 Otieno PO, Wambiya EOA, Mohamed SM, et al. Access to primary healthcare services and associated factors in urban slums in NairobiKenya. BMC Public Health 2020;20:1-9.

40 Annan J, Donald A, Goldstein M, et al. Taking power: women's empowerment and household well-being in Sub-Saharan Africa. World Dev 2021;140:105292.

41 Gupta S, Yamada G, Mpembeni R, et al. Factors associated with four or more antenatal care visits and its decline among pregnant women in Tanzania between 1999 and 2010. PLoS One 2014;9:e101893.

42 Haddrill R, Jones GL, Mitchell CA, et al. Understanding delayed access to antenatal care: a qualitative interview study. BMC Pregnancy Childbirth 2014;14:1-14.

43 Cigna. A guide to healthcare in South Africa, 2019. 